\title{
Research on the infiltration of cross-cultural awareness in higher education stage in the background of globalization
}

\author{
Xi Sun ${ }^{1}$ \\ ${ }^{1}$ Beijing University of Agriculture, 102206, Beijing
}

\begin{abstract}
At the university level, the penetration of cross-cultural awareness is of great significance to talent training. This article uses empirical research to study the cross-cultural adaptability of international students, and on this basis, puts forward four suggestions for the penetration of cross-cultural awareness among university students. This is of great significance for strengthening the penetration of cross-cultural awareness during colleges and universities, cultivating and enhancing the cross-cultural communication skills of college students, and adapting to the trend of global international communication.
\end{abstract}

\section{Introduction}

With the continuous development of the internationalization of education and the increasingly close international exchanges, my country's study abroad industry has shown a vigorous development trend, and talent training has basically formed a comprehensive, wide-ranging, and diversified international education exchange and cooperation pattern. The internationalization of higher education has, on the one hand, cultivated batches of high-level professionals for our country, on the other hand, it has also undertaken the mission of establishing a national image and spreading Chinese culture. Therefore, if university study abroad can become a messenger for spreading Chinese culture and cultural exchanges, and transmitting the "positive energy" of Chinese culture, it will surely make Chinese culture better spread to the world. The choice of college students to study abroad helps broaden their horizons, improve their independence, and cultivate the spirit of hard work. However, if the students have poor cross-cultural adaptability and insufficient mental preparation, it may also cause a weak sense of security, a decline in national and ethnic identity, and barriers to communication skills, which will prevent students from quickly integrating into the life of studying abroad, which will cause extreme thought and behavior on emotions and communication. Therefore, the penetration of cross-cultural awareness and the cultivation of cross-cultural communication skills at the university level are aimed at solving cross-cultural adaptation barriers and reducing the impact of cross-cultural adaptation barriers on students' study and life. According to the latest statistics from UNESCO's statistical agency, in 1975 , the number of international students receiving higher education abroad was 800,000 . In 2000, it reached 2 million. By 2010, a total of 3.6 million international students were receiving higher education abroad. By 2025 , the number will grow to 8 million, as shown in Figure 1.

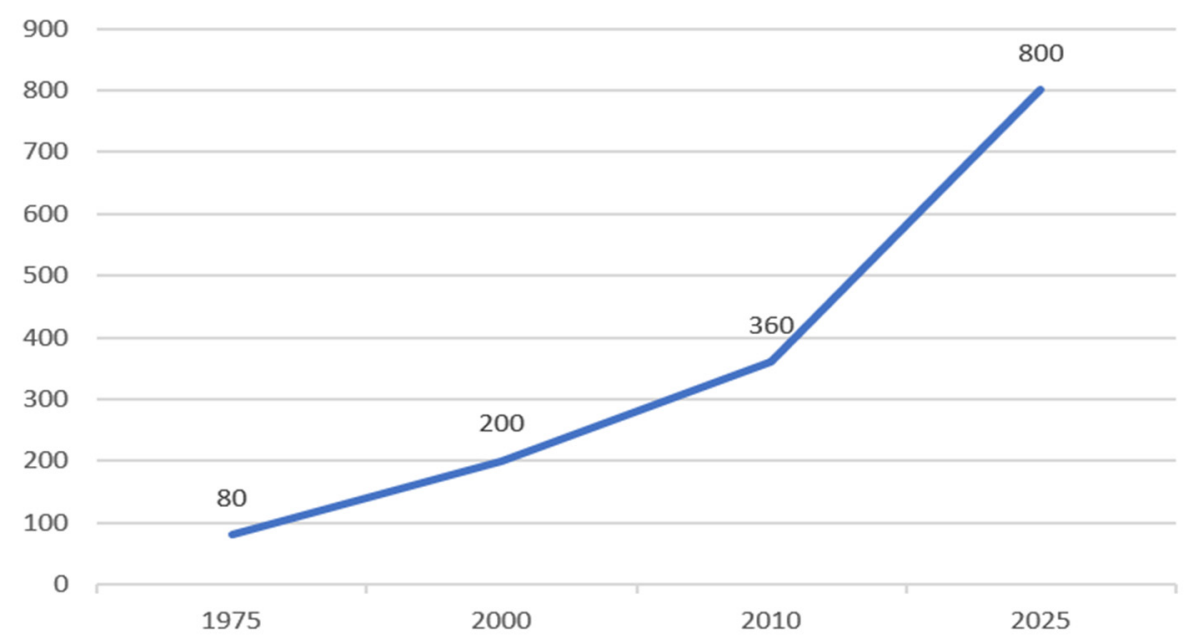

Figure 1. Statistics of the number of people receiving higher education abroad (ten thousand people) 


\section{Description of the basic situation of Chinese students studying abroad under the background of globalization}

The continuous expansion of international cooperation and exchanges in education has made China one of the countries with the largest number of students studying abroad. According to data from the Ministry of Education, the number of people studying abroad in China increased from 134,000 in 2006 to 703,500 in 2019, an increase of 4.25 times; from 2011 to 2019 alone, the number of students studying abroad increased from 399,600 to 703,500. See Table 1 for details.

Table 1. Statistics of Chinese students studying abroad

\begin{tabular}{ccc}
\hline Annual & $\begin{array}{c}\text { Number of students studying } \\
\text { abroad }(10,000 \text { people })\end{array}$ & Increase from the previous year \\
\hline 2019 & 70.35 & $6.25 \%$ \\
2018 & 66.21 & $8.83 \%$ \\
2017 & 60.84 & $11.74 \%$ \\
2016 & 54.45 & $3.97 \%$ \\
2015 & 52.37 & $13.90 \%$ \\
2014 & 45.98 & $11.09 \%$ \\
2013 & 41.39 & $3.58 \%$ \\
2012 & 39.96 & $17.63 \%$ \\
2011 & 33.97 & $19.32 \%$ \\
2010 & 28.47 & - \\
\hline
\end{tabular}

From the above data, it can be seen that the number of Chinese studying abroad is increasing year by year, the growth rate fluctuates greatly, and the willingness to study abroad is strong. Analysis of the reasons is that, on the one hand, with the increase in the income level of Chinese residents, the increase in family investment in education has made more parents willing and able to support their children in studying abroad. On the other hand, most students believe that they can better develop their own potential through living and studying abroad. At the same time, many employers have a positive evaluation of the employability of people who have lived and studied abroad.

Among the people studying abroad, we have made separate statistics on the countries studying abroad. The statistics are shown in Figure 2.

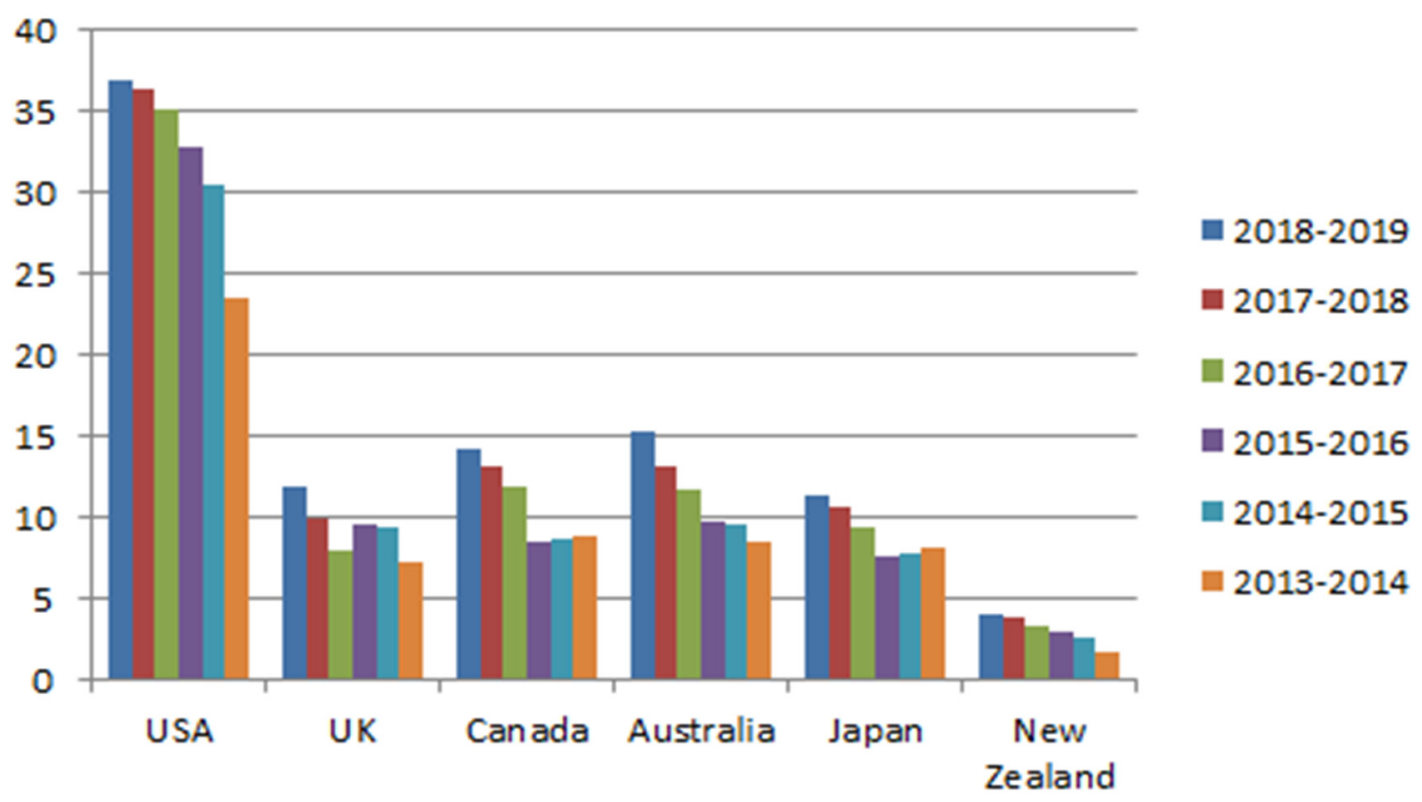

Figure 2. Statistics of Chinese students studying abroad 
From the above data, it can be seen that the United States, Australia, Canada, the United Kingdom, Japan, and New Zealand are popular countries for Chinese students to go abroad. Among them, the United States is the first choice for Chinese students to go abroad, and the number of international students is much higher than that of other countries. At the same time, since 2013, the number of overseas students has shown an upward trend, especially the number of Chinese students from the United States, Australia, and New Zealand has steadily increased in recent years.

China has a large number of students studying abroad, and the breadth and depth of the requirements for cross-cultural communication skills should be improved. Therefore, the cultivation of college students' cross-cultural communication skills is a new requirement for higher education in today's frequent global communication. At the university stage, the penetration of cross-cultural awareness is an important content and measure for colleges and universities to cultivate college students with an international perspective and the ability to communicate and communicate with each other.

\section{The current situation and inevitability of the penetration of cross-cultural awareness at the university stage in my country}

\subsection{Status}

At the university stage in our country, the educational awareness and teaching arrangement of cross-cultural awareness penetration are not prominent. On the one hand, the focus of cross-cultural adaptation focuses on the ability to use English language, so there are too many basic English courses, English professional courses and English communication courses. On the other hand, colleges and universities do not pay enough attention to the cultivation of talents with an international perspective. Based on the professional development of students, they do not cultivate the cross-cultural competence of international students. These two important reasons lead to the fact that the cultivation of cross-cultural competence in colleges and universities is not integrated into the education and teaching process. Generally speaking, the way for colleges and universities to cultivate cross-cultural competence is basically embodied in overseas study tours and exchange visits at home and abroad during the winter and summer vacations. However, whether it is overseas study tours or exchange visits between domestic and foreign students, due to the small audience, short training time, and low benefit, it does not meet the requirements of most colleges and universities to "train talents with international vision".

In the field of teaching and research, more teachers focus on the multicultural education and the cultivation of cross-cultural communication skills in English teaching, which have the characteristics of less integration channels and narrow integration methods. At the same time, this also shows that the teachers of professional courses do not have the awareness of cultivating students' cross-cultural competence. Although English teachers have the awareness of cultivating cross-cultural competence, they have not yet found a broader teaching approach on the aspects of understanding, action and implementation.

\subsection{Necessity}

3.2.1 The concept of "cultural co-prosperity and coexistence" under the background of globalization puts forward new requirements for the penetration of cross-cultural awareness in colleges and universities

With the continuous development of globalization, "cultural co-prosperity and coexistence" has moved from cultural diversity to cross-cultural tolerance and integration. Therefore, for my country's higher education, the cultivation of cross-cultural competence is not only an open understanding and perception of excellent foreign culture, but also an interactive inheritance of traditional Chinese culture.

\subsubsection{Talents with the ability of cross-cultural communication are national requirements for talent training}

Cultivating talents with cross-cultural communication capabilities and international literacy is a clear requirement of the country for higher education. The "Overall Plan for Promoting the Construction of World-Class Universities and First-Class Disciplines" mentioned that "the comprehensive quality, international vision, scientific spirit, entrepreneurial awareness, and creativity of students should be comprehensively improved." The "Outline of the National Medium and Long-term Educational Reform and Development Plan (2010-2020)" puts forward that "to train a large number of international talents with an international perspective, familiar with international rules, and able to participate in international affairs and international competition", "to strengthen international understanding education, to promote cross-cultural exchanges and enhance students' knowledge and understanding of different countries and different cultures." Therefore, cultivating a global citizenship with cross-cultural communication skills and international literacy and serving my country's international exchange activities is not only a student's own requirements, but also the positioning of higher education for the training goals of college students, and it is the country's demand for future talents.

\subsubsection{The process of college education is an important stage for the penetration of cross-cultural awareness}

At the present stage, college students have received enrollment education at the beginning of their schooling, and at the same time they have also received career 
planning education. This kind of education will make many students have some expectations and longings for their career development in the early stage of career planning. Although in this clear and hesitant thinking process, college students may not be able to clearly define the important role of intercultural competence in career development, but this anxiety or concern also reflects the lack of intercultural competence. Therefore, it is very necessary for students to integrate the content of cross-cultural education in higher education to improve students' cross-cultural communication ability and cross-cultural communication literacy.

\section{Cultivation of cross-cultural competence at the stage of higher education in China}

Although there are clear requirements in relevant documents such as the Ministry of Education, career planning should be incorporated into the whole process of talent training. However, as far as the current situation is concerned, at the stage of higher education in my country, the cultivation of cross-cultural competence has not been put in an important position in the cultivation of talents. The reasons why cross-cultural competence training has not been paid enough attention are mainly reflected in two aspects. On the one hand, it did not place the cultivation of cross-cultural competence in an important position of talent cultivation, did not arrange corresponding teaching courses, and did not make overall arrangements and layouts for the career planning of college students. On the other hand, some colleges and universities one-sidedly believe that the cultivation of cross-cultural competence is only necessary for students who intend to go abroad or English-related majors. Therefore, the arrangement of courses is relatively one-sided and highly targeted. It can be said that although many colleges and universities have clear expressions of "cultivating talents with international vision" and "core literacy with cross-cultural competence" in the talent training goals, they have not been reflected in the talent training process.

In order to enable students to better integrate into cross-cultural awareness and further increase the sense of national and ethnic identity, cross-cultural awareness needs to be penetrated during the education and teaching process during the university.

\subsection{The penetration of cross-cultural awareness} is both "internationalized" and "sinicized". The penetration of cross-cultural awareness mentioned here is "internationalization", and the emphasis is on cross-culturalism based on the premise of internationalization. But cross-culturalism is not just about internationalization, it is more about understanding the life, study, and culture of foreign countries. Blindly pursuing and understanding foreign cultures while neglecting the study and understanding of Chinese culture, there are in fact certain drawbacks. In the entire education system of our country, the learning, understanding and inheritance of Chinese traditional culture is limited to the knowledge of textbooks, especially Chinese textbooks. At the university level, there are no compulsory courses related to Chinese culture in many majors, and students' selective contact is also achieved through elective courses and club activities. Therefore, the time and opportunities for learning are relatively small, the scope of knowledge to be understood is relatively narrow, and the learning and understanding are not enough, let alone pass on. In this process, the demand for studying abroad with clear goals will cause students to pursue the penetration and understanding of cross-cultural awareness, and then ignore the study and inheritance of the country's excellent traditional culture. When we think deeply, we will find that cultural self-confidence plays a positive role in the process of cross-cultural adaptation. In the process of communicating with international students, cultural differences are one of the most important exchanges. In the process of cross-cultural communication, Chinese excellent traditional culture is often one of the points of interest that foreign teachers and students want to understand and communicate with. Cultural understanding and cultural self-confidence will play a positive role in the cross-cultural adaptation of Chinese students. Colleges and universities offer Chinese culture-related courses for students and dig deep into the content that is combined with the school's cultural characteristics. On the one hand, it is conducive to students' love and understanding of traditional culture, and on the other hand, it helps to promote students' mastery of the subject's knowledge and enable students really comprehend the true meaning of traditional culture, cultivate the character and character. Third, it is necessary and feasible to improve students' ability to express Chinese culture in foreign languages so that students can express Chinese culture in an appropriate way that conforms to the expression habits of people in foreign-language countries.

\subsection{The construction of cross-cultural adaptation of the integration of "first classroom" and "second classroom". The theoretical education of the "first classroom" is relatively boring, and the quality of the practical activities of the "second classroom" is difficult to grasp, which is a common problem. In terms of education and teaching arrangements, consciously integrating the "first classroom" and "second classroom" for cross-cultural adaptation education, on the one hand, it gets rid of the rigidity of theoretical education, and it can also make the "second classroom" more professional. And guidance, and then play the role and effect of intercommunication and mutual integration.}

\subsection{Construct a cross-cultural adaptation model that is coordinated at home and abroad. Many schools have joint training related programs and have deep contacts and friendships with foreign universities. When there are more exchanges between domestic and foreign universities, they often appear in the fields of scientific research, joint research and development,}


cooperative training and teaching. However, it ignores the educational significance and era significance of foreign universities in terms of the cross-cultural adaptability of college students. Not only in winter and summer vacations and summer camps, cross-cultural exchanges should also be placed in daily education and teaching, so that foreign college teachers can be integrated into daily teaching and interaction, so that foreign students and domestic college students can "pair" and participate in topics or Incorporate into the "Internet + community", enhance daily exchanges with foreign countries, and achieve the effect of cross-cultural adaptation.

\subsection{The construction of a comprehensive cross-cultural adaptation mechanism of "three-dimensional integration". The cross-cultural adaptation of college students should establish a comprehensive construction mechanism of "three-dimensional integration", that is, "psychology +} academic + society". Psychological adaptation is the main body of cross-cultural adaptation, that is, the yearning for the cross-cultural environment and the happiness and satisfaction of living in a cross-cultural environment. It is necessary for students to have a yearning for studying abroad, but they should have a more true understanding of studying abroad. They should not be partial, let alone blindly optimistic. For the students' colleges and universities, they should also provide psychological adaptation courses and lectures for students who are interested in studying abroad and are interested in understanding cross-cultural needs, so as to help students have a certain understanding of cross-cultural adaptation as soon as possible. Academic adaptation is to have an understanding and familiarity with the academic atmosphere of foreign countries, such as heuristic thinking training, participatory learning application, group discussion familiarity, literature search, classic case analysis, papers and essays, etc., the education and teaching methods commonly used in foreign learning should be familiar and adapted. Social adaptation can alleviate the barriers to cross-cultural psychological adaptation, so that students can better integrate into the cross-cultural social environment, which has a positive effect on cross-cultural psychological adaptation and cross-cultural academic adaptation. However, the cross-cultural social adaptation in domestic colleges and universities is still more at the stage on the theoretical level, which is far from enough to improve the adaptability of students and the prejudgment of cross-cultural social adaptation. This kind of social adaptation can meet the needs of students through some representative local cultural documentaries, travel guides, film and television materials, and personal experiences.

\section{Conclusion}

This article analyzes the important role of the penetration of cross-cultural awareness at the university stage and its significance to the cultivation of talents, and puts forward four suggestions for the penetration of cross-cultural awareness of college students at the university stage, which are very important significance for improving the international adaptability of college students and broadening their international horizons. But what needs special attention is that in the process of cultivating internationalization capabilities, it is necessary to strengthen the penetration and application of Chinese traditional excellent culture, so as to improve the dissemination and influence of Chinese culture.

\section{Acknowledgements}

This study is supported by the Key projects of the Ministry of Education in 2018 of the 13th five year plan of National Education Science ( DIA180388) 'Cross-cultural adaptability of cross-border higher education students in the background of globalization'.

\section{References}

1. Kireeva N , Chirkina L . "We Didn't Oppress Anyone": Peculiarities of Cross-Cultural Contacts in Mixed Families (Based on the Field Material from the Expeditions to Transnistria)[M]// Family and Family Values in the Slavic and Jewish Cultural Traditions. 2020.

2. Yu Rui.An Artistic Communication Strategy for Chinese Culture under the Cross-cultural Background[J] Journal of Jiangsu University (Social science edition), 2021,23(02):84-91.

3. Yi Li, Wu Dongying. Exploring new teaching mode in intercultural communication course: integrating case-based instruction with collaborative students' case composing $[\mathrm{J}]$. Exploration of higher education,2020(10):54-59.

4. Interdisciplinary Mentality and Transcultural Quality: The American Experience and Its Implications for Undergraduate Education in China $[\mathrm{J}]$. Journal of Nanjing Normal University (Social Science Edition), 2021(01):139-146.

5. Research on reform path of college English teaching from the perspective of cross-cultural communication [J]. Journal of Heilongjiang Institute of Technology,2020(12):68-71.

6. Daniel, M. Muia , W. M. Lucy, and M. M. Samuel . "Changing intergenerational relationships and their implications on family structure and functioning in Africa." (2013).

7. De L G M , Petithuguenin P, Le Gac I . Cocoa globalization and its impact on the international cocoa agreement[J]. Computational Statistics \& Data Analysis, 2000, 52(2):1234-1267.

8. D. B , Jones. Green Documentary: Environmental Documentary in the 21st Century by Helen Hughes (review)[J]. Film \& History: An Interdisciplinary Journal, 2016, 46(2):49-51. 